\title{
Diálogos desclassificados: a música e a voz por trás da teoria da desclassificação, segundo passo
}

Declassified dialogues: the music and the voice behind the declassification theory, second step

Klênio Barros ${ }^{1}$

Universidade de Aveiro kleniojbarros@ua.pt

Erickinson Bezerra de Lima

UNESPAR / PPGMUS-UFRN erickinson.bezerra@ua.pt 


\section{Apresentação 3}

¿Sería siempre necesario definir, demarcar, dividir? Ante la posibilidad de anestesiar la
significación sensible ¿no habría que suspender, rodear, desviar, antes que confinar o
asediar? o, a veces, ¿no bastaría explicarnos con una emoción?" (Gutiérrez, 2018, p. 24).

O conceito de desclassificação tem vindo a ser edificado e consolidado pelo epistemólogo espanhol Antonio García Gutiérrez ${ }^{4}$, desde 2006. Centrada numa perspectiva epistemológica que postula a diversidade dos mundos, da história, da cultura e de nossa própria vida, a desclassificação é um fermento de luta contra a imutabilidade que as categorias e as suas respectivas ordenações impõem amplamente a existência das diferenças. Entre o plano teórico-analítico e o plano prático das vivências e dos afetos, o presente escrito traz a exposição de experiências pessoais narradas numa entrevista concedida pelo próprio autor.

Professor por mais de quatro décadas nas universidades de Madri e Sevilha, García Gutiérrez é investigador visitante em vários centros latino-americanos, consultor de instituições internacionais e autor de prestigiadas obras no campo da desclassificação do conhecimento. Baseado na experiência deste livre-pensador o presente artigo procura dar luz à voz por trás da teoria da desclassificação. O objetivo central é oferecer subsídios teóricos e analíticos para o debate acerca dos desafios epistemológicos da desclassificação no domínio da Música, explorando possibilidades e variados modos de interlocução.

$\mathrm{Na}$ entrevista, optamos por utilizar todo o conteúdo das respostas na sua forma original e em língua espanhola. O intuito principal é não distorcer a voz, conservar expressões, preservar todo o conteúdo em essência e, as suas possibilidades de sentido, o que provavelmente qualquer tradução violentaria. Mantivemos, sem qualquer alteração, a ordem como o nosso interlocutor preferiu agrupar questões e respostas. Incluindo-se, na seção final, fragmentos selecionados e partilhados pelo próprio Gutiérrez, remetendo à suas obras, mais especificamente Frentes Digitales (2016).

\footnotetext{
1 Técnico em Música (2005), Bacharel em Música (2009) e pós-graduado em Música (2011) - Práticas Interpretativas do Século XXe XXI (UFRN/Brasil). É mestre em Música (2014), pela Universidade de Aveiro (Portugal). Atualmente, é doutorando em Música da Universidade de Aveiro, no ramo da Etnomusicologia. Desenvolveu atividade como docente de trombone, tuba e bombardino na Universidade Federal do Rio Grande do Norte.

2 Regente norte-rio-grandense e atuante nas vertentes artísticas e acadêmicas do Estado (RN). É Doutor e Mestre pela Universidade de Aveiro (PT) em Regência Orquestral, Pós-graduado em Regência com ênfase em Música Contemporânea e Música de Câmara, e Licenciado em Música pela UFRN. Desenvolveu atividade docente na área de regência na Universidade Federal do Rio Grande do Norte e na Universidade Estadual do Paraná. É pós doutorando do Progrma de Pós-Graduação em Música da UFRN.

30 presente texto é o segundo de uma sequência de artigos que abordam e abordarão a aplicação da Teoria da Desclassificação, enquanto suporte teórico, aplicado à música (Lima; Barros: 2020).

4 Ver: Connecting Research and Researchers. Disponivel em: https://orcid.org/0000-0001-5217-2611.
} 


\title{
Um diálogo desclassificado
}

\author{
Una mirada hacia sí mismo
}

EBL; KB: Pasos iniciales: ¿Quién es Antonio García Gutiérrez?

A. G: Si excluimos datos que solo tendrían interés para solemnidades del sistema académico, me gustaría que me consideraran simplemente como librepensador. Resulta utópico au-toclasificarse. Aprovechando la centralidad del verbo ser empleado en la pregunta in-troductoria, entraré directamente en algunos fundamentos de la desclasificación como contribución teórica transversal e incluso como modo de vida: el verbo ser es el que más conflictos y dilemas produce por su violento historial de definición y cierre. Parti-cularmente en sus "tiempos" presente y pasado. A veces juego a enunciar el mundo sin emplear el verbo ser, ni sus múltiples elipsis y sinónimos travestidos. Omitir la enuncia-ción omnipresente del ser, enviar su centralidad a nuestras periferias, parece discapaci-tarnos o devaluarnos, pero fugarse, o mejor, entrar y salir a voluntad del ser, del soy, del es, del fue y, por derivación ontológica, del yo, del nosotros, en suma, de cualquier demarcación o fortín esencialista, paradójicamente nos devuelve a nuestra naturaleza más contradictoria y polémica, pero también más real y diversa. El ser y sus modos cla-sificantes constituyen prioridades para las estrategias de desclasificación que contra-vienen la base de la lógica establecida.

\section{Trayectoria académica y génesis de las inquietudes}

EBL; KB: Con una producción académica tan considerable, nos gustaría conocer, de sus pro-pias palabras, un poco sobre su formación. ¿Usted podría tejer algunas consideraciones sobre su trayectoria académica? ¿Cuáles fueron las escuelas de pensamiento que influ-yeron en su formación?

A. G: Recibí una formación mediocre, rutinaria e hiperclasificada en las escuelas del nacional-catolicismo franquista. Hasta los 14 años hicieron de mí una persona altamente sumisa a los dogmas establecidos, tal vez con una facilidad para la atemorización por encima de la media. Pero cuando se siente su aliento tan próximo, el adoctrinamiento sin com-plejos muestra todas sus fisuras y debilidades de manera mucho más nítida que el dul-ce totalitarismo del consumo que detestaba Marcuse o, desde luego, que el totalitaris-mo sutil inoculados por los hipnotizadores digitales en nuestra intimidad -haciéndola adicta y cómplice- poniéndola a su servicio. Empleando sus armas digitales tan acríti-camente, todos somos soldados agradecidos a la lógica imperial.

La universidad y estudiar periodismo en Madrid a mediados de los años setenta no contribuyeron nada a mi capacitación crítica elemental, más bien 
al contrario, aun-que debo añadir que, salvo casos muy puntuales, las universidades del periodo consi-derado democrático han deteriorado seriamente la formación intelectual de la mayoría de los estudiantes, al trasladarles que ya todo estaba conquistado, dañando particular-mente la imprescindible dimensión autocrítica. Es cierto que trabajando como periodis-ta, en el primer periodo del posfranquismo, se consolidaron varios interrogantes insis-tentes. Lejos de rechazarlos me esforzaba en agrandar ese malestar psíquico que seña-laba Freud, necesario y previo a la negación y a las rupturas. Rupturas que con el tiem-po he intentado racionalizar sin organizarlas en exceso, dejando que el desgobierno también formara parte de un proceso en el que iba a intervenir de cualquier forma.

Desde entonces, elegí practicar la racionalidad -de entre el conjunto de las creencias- a sabiendas de su imperfección, de los axiomas y mitologías, como la objeti-vidad, de los que no logra desprenderse. Al contrario de los cartesianos, elegí la duda como fin y no como medio de alcanzar una certeza inútil. Elegí la racionalidad no con objeto de supraordenar creencias y emociones sino justamente para retornarla al lugar de reconciliación y empatía que necesitan las subjetividades y comunidades destroza-das por el individualismo y por el dualismo de nuestra violencia civilizatoria.

Respecto a la visión retrospectiva que tengo de mi trayectoria académica, en general está determinada por acontecimientos de nivel emocional más que por estudios o diplomas. Tal vez podría marcar un punto de inflexión a finales del verano de 1979, cuando me incorporé como investigador en el Press Research Centre de Cracovia gracias a una beca de posgrado de la entonces República Popular de Polonia. Uno de mis objetivos consistía en indagar las lógicas clasificatorias aplicadas a los estudios de comunicación de la época desde concepciones tan rivales como la capitalista y la marxista-leninista. Casi sin buscarlo, me topé con la evidencia de que no hay conoci-miento sin clasificación, de facto "todo conocimiento es su clasificación", y que hasta el conocimiento más riguroso se transmite mediante un lenguaje plagado de dicoto-mías, metonimias, ambigüedades, contradicciones, "accidentes" regulados por impla-cables leyes lógicas y epistemológicas cuyos fundamentos no se cuestionan lo suficien-te. Por ejemplo, la dicotomía implica una reducción porque organiza el mundo en pares de oposiciones, bueno/malo, hombre/mujer, norte/sur. Pensamos y expresamos el mun-do mediante dicotomías, a veces omitiendo uno de los polos, pero manteniendo la con-traposición, sin reparar en la reducción que suponen, y esto es así porque las dicotomías indudablemente producen conocimiento, pero exclusivamente un pobre conocimiento dicotómico. Cambiando de par o de oposición, se abrirían otros horizontes racioemo-cionales. Las contradicciones, por su parte, fueron abiertamente rechazadas por la lógi-ca tradicional y se adjudicaban a sofistas y timadores a pesar de fluir libremente en el pensamiento y en el comportamiento humano, desde luego de cualquier niño hasta que el 
bisturí de la domesticación se las amputa. Consideré que habría que rebajar esa con-dena milenaria del segundo principio de la lógica clásica dada su persistencia en todos nosotros. En lugar de desmantelarlas o desecharlas podríamos ponerlas a trabajar como recursos posepistemológicos que quebraran algunos límites, por ejemplo, para incorpo-rar la diferencia o la otredad mediante contradicciones y no mediante las reducciones o anulaciones que produce nuestra afirmación lógica.

Durante aquella estancia de investigación en Polonia, y aprovechando su cercanía, recuerdo que visité Auschwitz en seis ocasiones. En aquel espacio de dolor y desamparo, lo que lo convierten en un lugar sagrado -ahora desgraciadamente disney-landizado-, en unas ocasiones y como único visitante permanecía absorto ante los deta-lles personales de los asesinados custodiados tras las vitrinas, tal vez por la imposibilidad de calibrar la dimensión real de tanta crueldad. En otras, deambulaba por el exterior entre los crujidos del hielo invernal, intentando encontrar algún sentido a la maldad planificada por las elites del país más racional de Europa, en términos de Arendt una explicación provisional que no la justifica.

Obviamente no encontré esa explicación, salvo parcialmente y muchos años más tarde, convencido del carácter contradictorio que constituye la propia racionalidad su-puestamente infalible. Una razón al servicio y justificación de la pulsión y no al contra-rio. De ahí que en A ojos de la arena, un libro involuntariamente autobiográfico como descubrí tras escribirlo entre México y Marruecos, se advierta en sus primeras abstrac-ciones que "solo consigo entender el mundo como tragedia o como contradicción". Y que "elijo la segunda, sin olvidar la primera", sin duda para evitar disonancia cognitiva o un desarreglo mental. Desde luego, todo lo que he escrito o pensado desde entonces está atravesado por aquella circunstancia que constantemente observamos reactualizada en barbaries normalizadas, aceptadas o de digestión facilitada por las ondas totalitarias que nos atraviesan, organizadas en un eficaz sistema de coacción ambiental.

Creo, entonces, que en general más que por escuelas de pensamiento he sido in-fluenciado por experiencias como las expuestas y son estas las que hicieron de mí un voraz buscador de respuestas, pero muy fragmentario y diversificado en relación a es-cuelas, autores o tendencias.

EBL; KB: ¿Cuándo y en qué contexto surge, en su trayectoria, la teoría de la desclasifica-ción? ¿qué eventos históricos y/o personales marcaron la construcción de ese pensa-miento? ¿Hay alguna inspiración importante advenida de la producción latinoamerica-na? De ser así, ¿Cuáles serían?

Al hacer este análisis de su producción académica ¿sería posible señalar rupturas, as-pectos relevantes o desarrollo frente a sus propias obras, bajo la óptica de un autoanáli-sis? 
Aprendemos que "nada es contradictorio hasta pensar lo contrario" (Gutiérrez, 2020 p. 67). ¿Usted podría hacer algunas consideraciones sobre los retos de la desclasificación en los procesos de democratización epistemológica en América Latina?

A. G: Permítanme retejer estas cuestiones con el mismo hilo anterior. Fue en la Polonia de 1979, bajo férrea supervisión soviética, donde tomé conciencia de un sordo malestar simbólico justamente al estudiar la lógica y desarrollo de los sistemas de clasificación, pero de ningún modo surgió entonces un claro impulso desclasificador. Sin embargo, al regresar a la lógica capitalista un año más tarde, la percepción de señales totalitarias en todo tipo de valores, imaginarios y prácticas no cesaba de crecer por más que fuera creencia generalizada que había desaparecido el totalitarismo al morir un dictador co-mo Franco cuando, en realidad, en la historia del mundo el totalitarismo es la pulsión con mayor capacidad de adaptación y supervivencia. El capitalismo -como otros tantos abusos- sobrevive a sus contradicciones, a pesar de los vaticinios de Marx, simplemen-te porque habitan en el cerebro humano por más que algunos cuerpos doctrinales como la lógica, la epistemología o las buenas costumbres pretendan ignorarlas o acabar con ellas.

En cualquier caso, al regresar a España me esperaban otras urgencias inaplaza-bles que me obligaron a aplazar el trabajo que exigía mi desasosiego clasificatorio. De hecho, en la década de los ochenta me atuve a la perspectiva tecnicista dominante y mucho más práctica, exigida por la universidad y también por la sociedad, visión que trasladaría a mis estudiantes de comunicación de la Universidad Complutense de Ma-drid. Esa visión plenamente positivista fue reforzada por debates en el terreno de la Lingüística de la época y de otros presupuestos estructuralistas que dominaban en los círculos académicos franceses o brasileiros. De hecho fue en Brasil, primero como pes-quisador visitante del CNPq en la USP y posteriormente a lo largo de al menos veinte años de intercambios frecuentes, donde llegué al umbral y, seguramente por esto, supe-ré, la posición de una clasificación determinada primero por aspectos tecnicistas, des-pués lógico-lingüísticos, y más tarde epistemológicos y antropológicos, para terminar pensando la clasificación que opera en el interior de los sistemas como algo ubicable en un universo caótico mucho mayor que comencé a pensar como desclasificación sin ate-nerme a un nombre aún. Caos: concepto con el que nos aterroriza el orden establecido porque escapa a su dominio. Pero el supuesto desorden, o así lo imaginamos, será el único terreno fértil para la creatividad, incluida la que escasamente emana del orden.

En el mismo sentido, desclasificación no puede ser lo contrario de clasificación, cayendo en la trampa de una dicotomía general: lo contrario de clasificar sería "inclasi-ficar" o no-clasificar, una acción imposible. La desclasifi- 
cación implica un permanente proceso reclasificador en el cual tendría cabida cualquier orden porque hay muchos po-sibles, pero siempre quebrantables: "cuando ordeno algo, lo desordeno en sus demás posibilidades". Este mismo destino estaría aguardando a la epistemología. De ahí que no me entusiasme la expresión "epistemología(s) del sur", ni en singular ni en plural, re-tomando aquí una de sus preguntas, en referencia a las modalidades de construcción de los conocimientos autóctonos de América Latina. Epistemología no solo es una las-trada expresión eurocéntrica y antidemocrática, un "mero episodio de la cultura occi-dental" como decía Rorty, sino que introduce una lógica y una mirada rígidas desde el punto de vista desclasificado. Pero no son las cosas las que poseen un nombre, en realidad son esos nombres que les atribuimos los que las configuran o modifican. Para una mayor flexibilidad, "hermenéuticas del sur" podría ser una expresión occidental menos opresiva, pero al final igualmente innecesaria porque, "el sur", debe emplear sus propios nombres como parte de su construcción gnoseológica. En cualquier caso, aun entendiendo el carácter metafórico de sur, una metáfora cardinal no tiene por qué ser excluyente ya que, en términos desclasificados (estrategia $2^{a}$ de contradicción necesa-ria), todo sur es siempre también norte y viceversa, se contienen mútuamente y en to-dos los sentidos. En lógica desclasificada se impone una desidealización permanente frente a las ensoñaciones a las que nos invita el imaginario metafórico clasificado.

Aportaciones hay muchas: desde los clásicos trabajos de Gruzinski o Canclini hasta una rescatada concepción desde la teoría del diseño que redignifica la creativi-dad autóctona, pienso por ejemplo en el activismo y debates abiertos por Alfredo Gu-tiérrez Borrero y su proyecto DCOM (Diseño Con Otros Nombres) o en los trabajos de Arturo Escobar, particularmente sensibles en ese sentido.

Volviendo a la génesis de la desclasificación, aunque "si busco un origen lo ob-tendré y si hurgo un poco más obtendré otros", es posible que la experiencia que me proporcionó suficiente masa crítica para formalizar enunciados ya abiertamente descla-sificados fue el encargo que recibí del gobierno andaluz, entre 1995 y 1998, para orga-nizar el sistema conceptual de sus bases de datos sobre patrimonio histórico andaluz desde la prehistoria a la actualidad (y del que fue curiosamente excluida la música) en un mismo cuerpo clasificatorio (en formato de thesaurus). Para organizar partes del co-nocimiento en un solo lenguaje, primero fue necesario suspender las reclamaciones de propiedad conceptual que hacían las disciplinas representadas por los arqueólogos, an-tropólogos, arquitectos, historiadores del arte, geólogos y otros patrimonialistas que participaban en el grupo de trabajo. Por ejemplo ¿a qué especialista o ciencia pertenece-ría en exclusiva el concepto de arena o la arena misma? En trabajos teóricos posteriores ya se proponía el concepto de epistemografía como modo de organización transversal de los 
conocimientos científicos, pero se quedaba corto para comprender la clasifica-ción fuera de ellos. Las cadenas y jerarquías conceptuales son reflejo de las estructuras sociales a la vez que las refuerzan. Pero no se trataba de suprimir las jerarquías puesto que sería como no reconocer la existencia de privilegios derivados de una lógica de poder y dominación o de las actitudes indiferentes que siempre salen beneficiadas de los sistemas totalitarios. A nivel teórico, se trataba de mantener viva la relación jerár-quica a cambio de ser degradada, sometida a otros muchos modos de interacción. Del mismo modo sucumbe la lógica universal de la clasificación al ser incorporada y deva-luada por el pluralismo lógico de la desclasificación.

Por así decirlo, el salto -ya sin red- a la desclasificación realmente tuvo lugar al extender las reflexiones sobre epistemografía a las creencias y sus lastres simbólicos, incluyendo a la razón como una creencia más. Al pensar y publicar en trabajos distintos sus consecuencias sobre la memoria, la identidad, la cultura, la organización del cono-cimiento o la tecnología. Al elaborar estrategias orientadas a la emancipación de las partes respecto a sus todos quebrando la ancestral dicotomía mereológica (todo/parte) que todavía dirige con mano de hierro cualquier pensamiento contemporáneo, espe-cialmente donde nos creemos más a salvo, en la más apartada y desconfiada subjetivi-dad. Decía que sobre cada uno de aquellos conceptos abstractos publiqué un libro por separado, a pesar de ser realmente inseparables. Déficit derivado de tener que pensar el mundo desde la subordinación de su propio lenguaje, lo mismo que criticar las dicoto-mías utilizando dicotomías en la crítica. En En pedazos me propuse volver a unir lo que provisionalmente había "despedazado en partes" en aquellos libros, todavía dictados por la fuerte tradición disyuntora, bajo el epígrafe "el mundo en pedazos". Aun así, el proceso desclasificador es lento, lleno de trampas, y necesita reflexión en todas las áreas de un imaginario milimétrica e implacablemente clasificado desde la prehistoria.

La primera vez que utilicé y abordé abiertamente el propio término de desclasi-ficación fue en 2006 mediante una conferencia y un texto, bajo el título Científicamen-te favelados, presentados -en portugués- en un foro Unesco sobre Fronteras del cono-cimiento, organizado por la Fundação Biblioteca Nacional de Rio de Janeiro, presidida entonces por mi colega y amigo el profesor Muniz Sodré. Ese breve texto presentaba las bases de mi trabajo y su versión completa sería publicada en 2007 en el libro titula-do Desclasificados: pluralismo lógico y violencia de la clasificación.

Si queremos recuperar la diversidad del mundo, la diversidad de la historia y cultura de los pueblos, la de nuestra propia vida, incluso de la más íntima, obviamente el adversario es la inmutabilidad que las categorías y sus ordenaciones imponen a los relatos de esos pueblos, también a nuestros relatos interiores: nuestros secretos no están libres de clasificación. Pero la autonarración tampoco nos haría necesariamente más li-bres que ser descritos por terceros, por 
ejemplo, por un etnógrafo extranjero, si esa au-tonarración no logra librarse de su propia clasificación fosilizante. Los colonizadores de nuestra visión del mundo bien podrían ser nuestros propios antepasados, o ser noso-tros mismos los que perpetuemos, con una rigidez que es peor que el olvido, las vidas de ellos. He ahí la importancia del pluralismo lógico, también en la diacronía mnemo-gráfica, como proceso desclasificador de lo establecido, incluyendo la propia biografía. Un pluralismo que, en el tiempo, se entendería como un compromiso con la provisiona-lidad, con la revisión permanente, y que debe operar en la esfera de cada subjetividad para salir de ella y contagiar todo lo demás. Por eso la clave está en la autocrítica, otro elemento imprescindible de la desclasificación. Si al criticar nos proyectamos subjeti-vamente sobre lo criticado, debemos someter a crítica esa proyección, es decir, la auto-crítica del enunciador es inseparable de la crítica de lo enunciado.

Respecto a las influencias de tradiciones o autores académicos latinoamerica-nos, serían incontables, particularmente de mi larga e intensa relación con Brasil, y tal vez en parte mis posibles contribuciones constituyan un retorno agradecido a esa ma-tria maltratada que es América Latina, pero también como formas de cosmovisión que han inspirado trabajos concretos. Por ejemplo, en 2016 a lo largo de una estancia sabá-tica en Yucatán estudié las formas de pensamiento de los tojolabales, pueblo maya disperso entre Chiapas y Guatemala, particularmente a través de su lengua impregnada y transmisora de su cultura nosótrica. Trabajando durante meses sobre el monumental diccionario elaborado por Carlos Lenkersdorf, encontré y exploré los significados y contextos de la palabra x' etan: pedazo. Ella sola transportaba toda la cosmovisión nosótrica, por eso decidí revisar mis puntos de vista sobre desclasificación desde la modesta pero poderosa semántica de x' etan, En tojolabal no se emplea el concepto de parte sino de pedazo, esto es, si cae una cerámica al suelo no se divide en partes, se rompe en pedazos. Es exactamente eso lo que hacemos con el cuerpo, con la educa-ción, con la justicia, con el mundo al clasificarlos en partes, los despedazamos pensan-do que los dividimos racional, lógica o asépticamente. Una cultura que cree en la con-tinuidad solo ve pedazos donde nosotros vemos partes y considera que la continuidad no puede recomponerse ni pensarse desde la violencia de un despedazamiento. Este detalle fue lo que inspiró Frentes digitales. Totalitarismo tecnológico y transcultura, publicado en 2016 y, en 2018, En pedazos. El sentido de la desclasificación.

\section{Pensar la desclasificación en tiempos de pandemia}

EBL; KB: ¿Qué cosa nos puede enseñar la teoría de desclasificación en tiempos de encierro? ¿Cómo usted hace el análisis de las ganancias epistemológicas y los 
retos de esta infle-xión analítica para la construcción de una epistemología post-COVID? ¿Podría usted explicarnos cuál es la especificidad de su rasgo analítico?

A. G: La mente que ya siente en su piel el peso de las cargas simbólicas heredadas o impuestas percibe de formas distintas un confinamiento. Se puede permanecer voluntariamente en casa o en un monasterio sin sufrir la angustia psíquica de un encierro. Sin embargo, a veces en la naturaleza abierta puede sentirse el confinamiento opresor de la clasifica-ción a través de las múltiples señales de obligación o prohibición que nos amenazan en todas partes, de la hiperregulación del espacio y del tiempo mediante geosímbolos y cronosímbolos estratégicamente situados, recordatorio de nuestras fronteras simbólicas por coacción ambiental. La sensación de confinamiento solo es mental porque no hay órgano más confinado que el cerebro tras su blindaje craneano. Y la evolución no cons-truye fortalezas arbitrariamente.

Nuestro nivel de clasificación es tal que solo entendemos la diferencia mediante categorías y jerarquizaciones propias, esto es, no la comprendemos sin la violencia de una sustitución. Esta ha sido una de las obsesiones de la traducción cultural para no al-terar al otro, pero en términos desclasificados es como deshacer contradicciones para entenderlas en un lenguaje que las destruye, en lugar de dejar intacto su potencial se-mántico y heurístico: finalmente la diferencia persiste en tanto no se traduce ni homo-loga, en tanto aceptamos algo en toda su contradicción. Y la contradicción nos enri-quecería doblemente si aprendiéramos a abrir el pensamiento creando y utilizando enunciados contradictorios. La contradicción, como la clasificación, no forman parte de la naturaleza ni provienen de ella, y si lo fueran nunca llegaríamos a verificarlo por-que las contradicciones, los conceptos, como las cosas que percibimos, tienen lugar ex-clusivamente en el mundo interior que crean nuestras representaciones mediadas por la clasificación. Son juegos del imaginario individual o "colectivo", aunque sus conse-cuencias no suelan ser imaginarias sino a veces bien físicas y hasta cruentas, por lo que ese sería el espacio en el que deben desencadenarse los proyectos desclasificadores. Es-to incluye, por supuesto, los propios procesos de raciocinio, los que con mayor urgencia deben ser desclasificados porque nos convencen de una objetividad infalible cuando realmente también operan dentro del imaginario.

Respecto al Covid-19 ¿alguien pensó recién terminada la Gran Guerra que 21 años después comenzaría otra mucho peor? ¿A alguien, tras la $2^{-}$ Guerra, se le ocurrió que medio siglo después se desangrarían nuevamente los Balcanes? Las guerras son desencadenadas por intereses de las minorías en el poder, pero por consignas y creen-cias identitarias se llenan las fosas: de ahí que sea urgente desclasificar las identidades y demás imaginarios.

La pandemia de COVID-19 es otra tragedia para la humanidad asociada a un determinado modo de vida, de movilidad y saturación, pero siempre es 
necesario poner en positivo las experiencias. Desde luego, en términos "devolucionarios" nunca pudi-mos imaginar que un simple virus iba a propiciar el decrecimiento hasta casi detener la sobreproducción salvaje de mercancías o a reducir drásticamente la polución. Mi visión es pesimista en cuanto a esto porque la sobreproducción regresará con más euforia con-sumista si cabe. La mayor producción capitalista consiste en fabricar clasificados acríti-cos que consuman compulsivamente. Entonces, no veo indicios de epistemologías postcovid en el escenario de una política científica y académica orientada por las polí-ticas económicas de la sobreproducción. Al parecer, para algunos esta catástrofe no ha sido suficiente. Por otra parte, esta pandemia también ha puesto de relieve que el sujeto contemporáneo no se autocontrola por responsabilidad propia sino exclusivamente ante medidas coercitivas o por miedo, es decir, vivimos en sociedades altamente irresponsa-bles. Esto es demoledor porque nunca creímos que millones de personas alfabetizadas apoyarían a déspotas declarados como Trump, aunque tenemos el precedente de un Hitler electo que no ocultaba sus intenciones. Cuando en Croacia la mayoría de la po-blación católica votó en contra del matrimonio gay en un referéndum, amputando de-rechos civiles que no afectaban a esa mayoría de votantes, tuve que revisar mis convic-ciones sobre la democracia participativa. Cuando la democracia se usa contra las liber-tades de las minorías, estamos ante un serio problema. En diciembre de 2020, el Parla-mento español aprobó la ley de la eutanasia. Ante la fuerza del clero y de la derecha posfranquista, dudo que mediante referéndum hubiera sido aprobada la misma ley, aunque se trate del derecho indiscutible a no querer sufrir.

\section{La música y la desclasificación}

EBL; KB: Sabemos que usted es un enamorado de la música. ¿Qué es lo que más lo atrae en este campo?

A. G: Desde hace mucho tiempo, y particularmente por la saturación de opiniones y la infoxi-cación que producen, intenté sin éxito practicar la suspensión del juicio, alcanzar la ataraxia de los escépticos. La capacidad que tiene para suspender la racionalidad: eso es lo que más me atrae de la buena música. No obstante, e interpretando libremente a Spinoza, añadiré que no seleccionamos la música buena, es buena porque la seleccio-namos.

EBL; KB: En su opinión, ¿cómo pueden las practicas musicales contribuir para el debate ac-tual acerca de la violencia clasificatoria? ¿De qué forma la música aún estaría en diálo-go con su pensamiento? Frente a eso, ¿por qué en sus libros mas recientes usted ha pri-vilegiado a los prólogos que ponen la música en diálogo con la desclasificación? 
A. G: La música es uno de los espacios que más voz presta a las emociones. Sin embargo, al desidealizarla nos encontramos con reproducciones de las mismas viejas estructuras de poder e intereses, clasificaciones y cánones que obedecen a lógicas totalitarias que deben ser desclasificadas. Porque su jerarquía es explícita, sabemos que el ejército obedece a una lógica establecida en las escalas de mando. Pero también de un cierto modo militarizado se comportan los demás sistemas incluida la música. Pensemos específicamente en la música abiertamente proyectada a la imposición o la sumisión como las marchas militares o los himnos nacionales, pero otros géneros musicales no se libran de una cierta intencionalidad hímnica, propagandística, mercantilista, y tampoco los modos como son interpretados, conservados o estudiados. Es importante descifrar las estructuras intencionales de la música, su lógica y órdenes ocultas, sus claves militarizadoras en el marco de la continuidad del mundo. La música no tiene enemigo al que vencer.

La clasificación contiene un toque de corneta interior, una constante llamada a sus filas. La desclasificación propone la autoinsurgencia simbólica. Pero la música no solo es una metáfora aquí, va más allá del phoroi teniendo ella misma un poder tan liberador como alienador. Donde hay sapiens se instala un totalitarismo clasificador que salta de la mente a las relaciones: la desclasificación es una prevención respecto a nosotros mismos. Desvelar esa lógica totalitaria en las moléculas del sistema musical sería el objetivo de la desclasificación como contribución de un programa transversal que afecta a todos los modos de expresión o percepción humanos. Infelizmente mi pasión desbordada por la música no compensa mi ignorancia en ese terreno, así que no me corresponde realizar ese trabajo desclasificador y sí a músicos y musicólogos. El hecho de haber contado con prologuistas como Susana Sardo o Luca Chiantore se de-be a su sensibilidad desclasificada respecto al universo musical. Al tener noticias de sus programas académicos o interpretativos, se produjeron contactos e intercambios cuyos resultados pueden verse ya en proyectos y publicaciones.

EBL; KB: ¿Cuáles son sus siguientes proyectos o planes de investigación? ¿Cuáles diálogos que están por venir?

A. G: Tras la lectura de A ojos de la arena, colegas muy próximos me expresaron con sinceri-dad la incomodidad simbólica que les producían diversos pasajes del libro. Entendí, entonces, que estaba en la línea correcta y decidí apuntar la desclasificación hacia es-pacios más íntimos.

Ese proyecto seguramente llevará como título Tout droit, metáfora de la rigidez de las vías de hierro por las que circulaban los trenes de prisioneros hacia un destino trágico que desconocían y a los que a veces aguardaba música de Schubert en los an-denes. De algún modo, nuestro imaginario 
transita por inflexibles direcciones simbóli-cas que no nos permiten ver otros paisajes, cambiar de escenario o simplemente elegir otras opciones más allá de las dicotomías, del binarismo o de la consistencia del dogma de turno. A nadie se le invita a elegir su clasificación, por tanto todo lo que se constru-ye carece de plena libertad en la fundamentación, pero el ofrecimiento tampoco surge más adelante. Lejos de eso, en la cultura cristiana, por ejemplo, tras el bautismo hay una comunión y después nada menos que un rito de confirmación y sellado de todo lo anterior. La clasificación llena de rituales todos los espacios del imaginario. Lo lleva haciendo miles de años y no facilita huidas ni rupturas salvo a mentes desterradas que lo hacen por su cuenta. En un momento dado debería tenerse esa oportunidad de elec-ción, pero para eso es necesario una invitación a conocer otros órdenes incluido el su-puesto desorden. En mi trabajo actual intento vislumbrar las actuaciones de la clasifi-cación en los confines de la intimidad especialmente en aquellos velados por la discre-ción, los secretos, la sexualidad, los tabúes y prejuicios, pero también me ocupo del os-curantismo que no cesan de reproducir las viejas categorías incuestionables. En cual-quier caso, mantengo vivos mis objetivos generales: rehabilitar una subjetividad auto-crítica, avanzar en el pluralismo lógico radical, reincorporar los recursos proscritos por la lógica tradicional en los procesos racionales como la contradicción, la ambigüedad, la impureza, la emoción, el elogio de la diferencia.

En relación a ese último horizonte, me gustaría finalizar con unos fragmentos de El placer de la diferencia ["Frentes digitales"] (2016, p. 195-199), un relato de sensa-ciones desclasificadas que termina con música:

Solo el inconsciente de su propia ignorancia acusaría a alguien de ignorancia. Solo un patriota sería capaz de zaherir a otro patriota por su patria diferente. Solo un creyente podría insultar a otro creyente con quien no comparte credo.

A causa de la proliferación histórica de ignorantes, patriotas y creyentes, se exten-dió la normalidad de la barbarie cognitiva, xenófoba, ideológica. El mundo con-temporáneo asiste a ella con asombrosa naturalidad. Esa franqueza dañina del in-diferente ante la diferencia es denunciada en la desclasificación. El sabedor de su ignorancia no tiene con quién rivalizar. El apátrida de corazón no tiene bandera que despreciar. El agnóstico que duda no tiene culto que blasfemar. El sujeto desclasifi-cado no consideraría al otro como oponente sino tan solo como admirado distinto.

La fascinación por aquella cultura no residía en su estética exótica, ni en sus llama-tivas tradiciones, ni siquiera en su deliciosa gastronomía tan decisivamente condi-mentada de creencias. La fascinación brotaba de la incapacidad absoluta de com-patibilidad, de traducibilidad, de comprensión. Mas esta no sería una actitud de re-chazo, ni tampoco de tolerancia o respeto, prepotente dádiva que nunca nadie de-bería permitirse obsequiar. Mi fascinación por aquella cultura radicaba en un sen-timiento de pérdida absoluta, de incontrolable deriva, de descontexto, aun persis-tiendo alguna suerte de pulsional clasificación interior en continuar rigiendo. No me embelesaba ya la revelación posible, sino la ocultación grosera, indelicada, la fuga de tanta subjetividad ante mis atrincheradas 
y sorprendidas estructuras. Sin su indi-simulada voluntad de ausencia todo el poder de encantamiento se desvanecería al hacerse entendible. Su obscenidad, y mi atención, entonces, se encontraban en la pericia del camuflarse, en la legítima cripsis, en la elegancia -siempre dolorosa- de la desaparición. Hube de cambiar de coordenadas perceptivas para experimentar ca-da nuevo instante de otro modo: aprender sin comprender, incorporar sin recordar, ser sin saber. Así, hasta la irrecuperable evanescencia del momentum. Y, más tarde, solo retorno al vacío opresor del concepto.

Placer de la diferencia, no ofrecida por el otro, sino procurada intensamente como adicción que me haría regresar una y otra vez al lugar genuino, con mayor angustia en cada viaje, por temor de no encontrarla igual y por eso, una vez más, distinta. No comprender se convirtió, entonces, en una lucha sin tregua por no querer com-prender, ante la presión creciente de la homologación, de la analogía, de la regula-ción, de la interpretación forzosa. No prestarse a estrategias de aproximación, de automatismo, de hacer cognoscible lo inconmensurable, ni visible lo invisible, ni ha-cer hablar a los callados, vivir el acontecimiento de lo irrelevante sin un solo foto-grama, respirar un presente irregistrable, se transformó en espontáneo cálculo, en la alegría de lo inesperado. Y, también, en esperanza. La distancia mantenida hacia aquel mundo reacio, de voluptuosa ausencia, me dispensaba oxígeno, reservas de diferencia para sobrevivir un tiempo. No era momento de aferrarse a timón alguno sino para sentirse, por un brumoso instante, fuera de toda cultura. Incluso de la que una vez fuera propia, la cual, a fuerza de negarle la traducción ajena, por momen-tos regresaba menos imperativa al tiempo que más auténtica. Y ese goce pleno de la diferencia, de autonegada medida, se convirtió en una búsqueda y ya, también, en obsesión.

El empeño racional en no comprender será, no obstante, inversamente proporcional a la angustia vital de presentir. Al impulso inaplazable de captar aquella melodía in-tramuros, tan imperceptible como penetrante a tan escasos decibelios. Lejos al la-do. La incomprensión calculada podría quedarse en una suerte de curiosidad in-conclusa pero plenamente satisfecha. Lo mismo que, al oír una hermosa música, no se precisa de entendimiento alguno, de cultura alguna, solo de la pasión de sentir lo fugaz, lo inasible, lo que se escabulle al otro lado de la lógica. Puertas, velos, mu-ros de piedra o adobe, mitigarían cualquier tentación de interpretar, de registrar, de apropiarse, de reproducir lo percibido. Solo concederían la fruición de incompletud, de omisión, de desconcierto. Restaría, entonces, el placer de perderse en la diferen-cia, en el otro imaginado y, por ello, intacto ante la demolición de la lectura. Y la fortuna de aquella música, turbadora, inaudita. (cultura amazigh, antiatlas, 2013).

\section{Um apontamento parcelar}

Compreende-se, por fim, a importância da luta e do pensamento de Gutiérrez, que convoca a desclassificação não só como um espaço aberto para a pergunta, onde o diálogo interdisciplinar e de pluralismo lógico deveria superar o testemunho passivo, mas também como um espaço transfronteiriço de convergência de vozes, a procura da irrupção epistêmica para explicar o processo de organização dos signos em outros. A(s) voz(es) por trás da teoria da desclassificação tenta $(\mathrm{m})$ cumprir o espectro desta árdua tarefa. Obrigado Antonio García Gutiérrez por ativar nossos sentidos. 


\section{Referências}

GUTIÉRREZ, Antonio García. En Pedazos. El sentido de la desclasificación. Madrid: ACCI Ediciones, 2018.

GUTIÉRREZ, Antonio García. Cientificamente favelados: uma visão crítica do conhecimento a partir daepistemografia. Transinformação, Campinas, v. 18, n. 2, may/ aug. 2006. Disponível em: http://dx.doi.org/10.1590/S0103-37862006000200002 Acesso em: 20 dez. 2019.

GUTIÉRREZ, Antonio García. Desclasificados: pluralismo lógico y violencia de la clasifica-ción. Barcelona: Anthropos, 2007.

GUTIÉRREZ, Antonio García. La identidad excesiva. Madrid: Biblioteca Nueva, 2009.

GUTIÉRREZ, Antonio García. Pensar en la transcultura. Madri: Plaza y Valdés Editores, 2011.

GUTIÉRREZ, Antonio García. La organización del conocimiento en el nuevo orden transcul-tural: del totalitarismo a la desclasificación. Brazilian Journal of Information Science, v. 8, n. 1-2, parte I: 19, parte II:34, 2014. Disponível em: http://revistas.marilia. unesp.br/revistas/in-dex.php/bjis/issue/view/289 Acesso em: 1 jan. 2020.

GUTIÉRREZ, Antonio García. Frentes digitales: totalitarismo tecnológico y transcultura. 1 Ed. Salamanca, España: Comunicación social ediciones, 2016.

GUTIÉRREZ, Antonio García. A ojos de la arena: ejercicios de desclasificacíon. Madrid: ACCI Ediciones, 2020.

LIMA, Erickinson Bezerra de; BARROS, Klênio. ORFEU - Revista do Programa de PósGraduação em Música da UDESC, v. 5, n. 2, p. 01-21, 2020.

QUEIROZ, Luis Ricardo Silva. Traços de colonialidade na educação superior em música do Brasil: análises a partir de uma trajetória de epistemicídios musicais e exclusões. Revista da Abem, Londrina v. 25, n. 39, p. 132-159, 2017. Disponível em: http://www. abemeducacaomusical.com.br/revistas/revistaabem/index.php/revistaabem/article/ view/726. Acesso em: 04 mar. 2021.

RORTY, Richard. Education, philosophy and politics. England: Rowman \& Littlefild Publishers, 2001. 


\section{Agradecimentos}

Agradecemos imensamente ao professor Antonio Gutiérrez pela disponibilidade e incentivo acadêmico, o que nos deixa cheios de entusiasmo e vontade de continuar na "luta" contra à insensibilidade acadêmica, reflexiva e musical.

Agradecemos à Taise Bezerra de Melo pela prestimosa colaboração com as particularidades intrínsecas à língua espanhola. 